\title{
Use of Video and 3D Scenario Visualisation to Rate Vegetation Screens for Integrating Buildings into the Landscape
}

\author{
Jacinto Garrido Velarde ${ }^{1, *}$, María Jesús Montero Parejo ${ }^{2}$, Julio Hernández Blanco ${ }^{2}$ and \\ Lorenzo García Moruno ${ }^{2}$ \\ 1 Department of Territorial Sciences, University of Extremadura, Cáceres 10003, Spain \\ 2 Department of Graphical Expression, University of Extremadura, Plasencia 10600, Spain; \\ cmontero@unex.es (M.J.M.P.); juliohb@unex.es (J.H.B.); igmoruno@unex.es (L.G.M.) \\ * Correspondence: jgvelarde@unex.es; Tel.: +927-25-70-00
}

Received: 20 April 2017; Accepted: 19 June 2017; Published: 23 June 2017

\begin{abstract}
Human actions in the natural environment create a visual impact. The main objective of this study was to examine the acceptance of vegetation screens for integrating buildings into the landscape using new techniques of visualization in three dimensions (3D), videos and public participation. The status quo of two study areas representative of the Mediterranean climate in Spain (one inland and one coastal) was modelled, placing vegetation screens around a building typical of the area and varying the density, species, and layout of plants. After establishing a series of scenarios, videos showing a simulation of outdoor tourism activities performed at varying speeds were created to analyse how movement affects the perception of the combination of a building and vegetation screen in the versions created. The 3D models generated were subjected to a survey for public participation and to allow respondents to rate their preferences of the videos created. The results show that adding vegetation always improves the integration of buildings into the landscape. The most highly rated vegetation screen placed around the buildings in the two scenarios was high density vegetation, irrespective of the layout or species.
\end{abstract}

Keywords: landscape; buildings; vegetation screens; visual impact; 3D visualization; videos

\section{Introduction}

\subsection{Aproach to the Problem}

Integrating scattered rural buildings into the landscape within the framework of a sustainable territorial model is a challenge for land-use planners. It can also provide an opportunity for entrepreneurs, particularly in tourism, by responding to a growing social demand and increasing the added value of products [1,2].

The proliferation of buildings in rural areas, where architectural typologies are often far removed from traditional models, has resulted in a loss of landscape values in these spaces. Integrating these buildings into the landscape appropriately is a key step towards preserving the landscape quality in rural areas, and provides an essential tool for rural development policies [3,4].

The visual quality of a built-up area is important due to the economic and aesthetic connotations. Because decisions that modify this type of area have long-lasting effects, it is essential to understand the effects of proposed changes before they are implemented. One way of doing this is to view modifications using computer simulations to assess their impact [5]. 


\subsection{Landscape Visualisation}

Visualisations have been used throughout history for communication between human beings [6]. Three-dimensional physical models have been in use for hundreds or even thousands of years. In the Renaissance, perspective gave widespread importance to drawing and painting in representing existing or imaginary buildings [7,8]. In the history of landscape architecture, Repton [9] can be considered a pioneer in the field of landscape visualisation [10]. In his "Red Books", Repton proposed a technique for rendering a landscape design perspective that is not unlike present day methods.

The emergence of digital computer visualisations in the late 1980s made it possible to create digital photomontages, and the development and availability of costly software opened up new possibilities for landscape planners. Since then, landscape visualisation technology has grown significantly, generating many different techniques and methods for this task [6].

The method of image draping consists of placing a single image or a combination of images over a 3D terrain representation. Owing to the low complexity of information, this method makes it easy to navigate freely and at high speed in the setting generated. Although it is convenient for an overview of large areas, image draping lacks resolution at viewpoints close to the ground [11].

Photorealistic representations of vegetation and other landscape features are used for an improved, more realistic simulation of an area. A high degree of realism is the main advantage of this approach, although the output is not interactive [12,13].

The virtual reality (VR) method comprises fully interactive systems that let the user fly or walk through the composition, obtaining various points of view. This aspect of VR is similar to a real life experience and gives users the chance to discover a place rather than just seeing and contemplating a simulated space [14]. However, objects are often simplified to shorten the time for the representation process, leading to reduced realism and confused orientation.

\subsection{Animation and $3 D$ Visalisation}

In recent decades, contemporary western society has shifted from a world dominated by digital immigrants to a society and a professional context dominated by digital natives [15]. The tools and techniques employed to represent our world in 3D visualization have entered our everyday lives. Babies can be seen in the womb in 3D scans. Children, parents, and even some grandparents play 3D video games. Soon we will be watching TV in 3D and viewing 4D multisensory cinema. Google Earth software (Google, San Francisco, USA) allows us to navigate and explore remote regions in perspective views using data transmitted via the internet [16], showing 3D representations of the landscape with a wide range of textual information [15].

Visual representation techniques have become a commonplace research tool, compared to their sporadic use in previous decades. Physical models, drawings and images have quickly evolved into internet-based virtual realities and visualisations [15].

3D landscape visualisations have evolved since their beginnings, when they required costly technology and specialised equipment, into 3D visualisations via free software (Google Earth) using non-specialist equipment (basic computer skills). Increasing the scope for phone or tablet-based tools such as Layar [17] offers new opportunities for communication in landscape settings [18]. In the last few decades, digital landscape representations have shifted from abstract, static renderings to realistic visualisations that can be explored by dynamic spatial movement. This offers the potential of an immersion experience in multiple spatial and temporal scales. Computer-generated 3D models can be seen from all angles, providing the viewer with a visual experience of an environment yet to be built [19]. Technological advances mean that it is increasingly rapid and easy to sketch out a design and finalise details with the application of a range of software.

Conniff [19] and Gosling [20] recognized the potential value and the importance of presenting questionnaire respondents with proposals for "strolls" through an urban design. Some researchers have questioned the perception of the environment using static images (photographs) when we normally experience the world around us via a flow of changing visual images. Although the scientific 
community accepts that photographs evoke responses similar to those felt when actually in the location represented [12,13], Heft \& Nasar [21] found that reactions to static screens are not the same as reactions to screens in motion. These authors reported significantly lower respondent ratings for static scenes than for dynamic scenes. This finding has implications for the way in which designs are presented to people, because although a building and its setting may appear attractive in a drawing or computer-assisted design model (CAD), we do not usually observe buildings statically. It could therefore be argued that video presentations of future settings conjure up perceptions and reactions that are closer to what we encounter in the real world, in detriment to those evoked by static images [19].

The use of digital representations based on digital or virtual settings is well established in land-use planning and has become a common feature of landscape and town planning. However, few studies have indicated that visualisations can also fulfil the purpose of internal communication between experts from different disciplines (or within a single discipline) working on a shared project. In terms of content, landscape visualisations still commonly focus on the final product of a planning and design process intended to communicate with the public or potential clients [15].

The main objective of this study is to examine the integration of buildings into the landscape by visualising scenarios in three dimensions (3D) using videos and study techniques that encourage greater public participation [22]. The 3D scenarios modelled are based on two study areas representative of the Mediterranean climate, one in the north of Extremadura and the other in the south of Huelva (Spain). As well as the 3D modelling of the status quo of the two study areas, vegetation screens were placed around a typical building, varying the density, species, and layout of plants. The 3D models generated were submitted to a survey to facilitate public participation and assess the respondent preferences of the videos generated.

\section{Materials and Methods}

\subsection{Study Areas: Plot Selection}

Two experimental research zones representative of the Mediterranean climate was chosen, in order to apply the results of this study to areas with similar characteristics: one representative of rural settings in the district of Ambroz Valley, in the north of Extremadura (Spain), and another in the south of Huelva (Spain), corresponding to coastal settings (Figure 1).

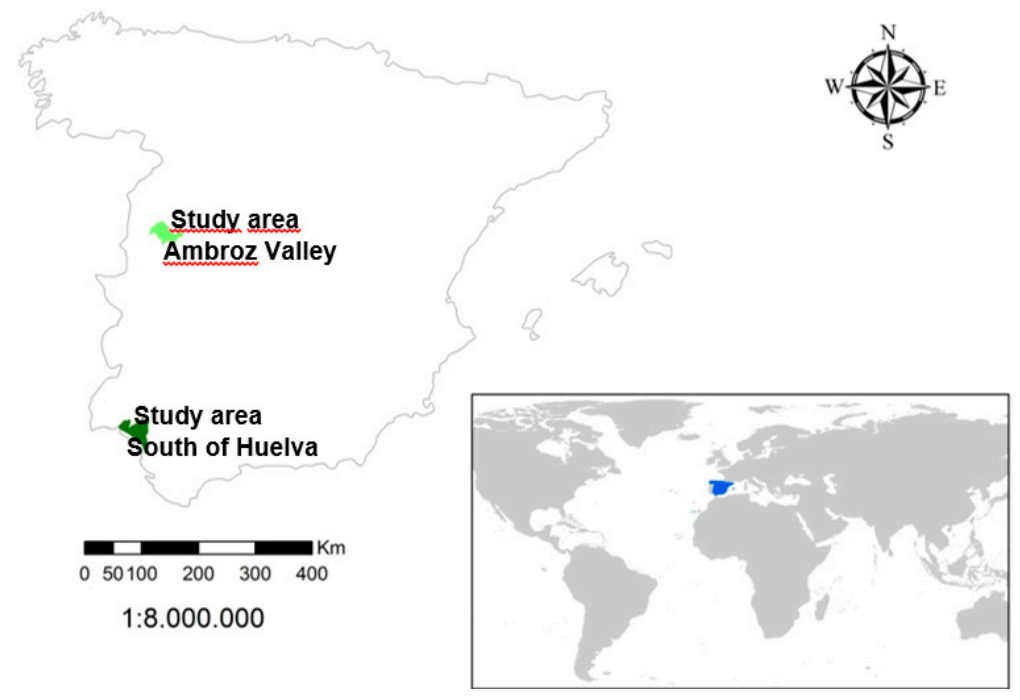

Figure 1. Location of the study areas representing a rural setting (Ambroz valley) and a coastal setting (south Huelva). Source: Compiled by the author from NCGI (National Centre for Geographical Information) data. 


\subsubsection{Ambroz Valley Study Area}

Ambroz Valley, the experimental zone in a rural setting, is in the municipality of Hervás, in the north of Cáceres Province (Spain), in the foothills of the Gredos and Béjar mountains.

The physical environment of Ambroz Valley has a natural diversity of high quality due to the range in altitude, from 400 to 2,102 m. It therefore provides optimum growing conditions for sustainable mature woodland.

The woodland systems in Ambroz Valley are:

- High mountain woodland, where the climate is favourable for heather, cytisus spp, broom, high mountain pasture, moss, and lichen.

- Atlantic woodland, which is deciduous and rich in vegetation such as sweet chestnut, oak, holly, and yew.

- Mediterranean woodland, comprising holm oak and old cork oak woods, areas under crops, and irrigated flat-bottomed valleys. This system is found at lower altitudes.

After characterising the vegetation in the study area, a field visit of buildings and woodland masses was conducted to determine the natural and built features of the valley. The objective was to select buildings in the natural environment where the methodology of the research project could be applied.

To standardise the method, a search was made for vegetation and building combinations typical of Ambroz Valley.

Each building and vegetation element within the study plot was measured using the VERTEX Laser Hypsometer (height of building, height of adjacent vegetation), and the UTM coordinates were taken for processing in a Geographic Information System.

\subsubsection{South Huelva Study Area}

Part of the Cartaya municipality was chosen as the coastal experimental area, because it is representative of town planning activities associated with woodland in coastal areas.

The municipality of Cartaya has 17,424 inhabitants in an area of $226 \mathrm{~km}^{2}$ and an average height above sea level of $26 \mathrm{~m}$. Although the main urban nucleus is $9 \mathrm{~km}$ from the coastline, there are two urban developments by the sea: El Rompido and El Portil, $7 \mathrm{~km}$ apart. Between these three nuclei is a forest area known as Pinares de Cartaya, comprised of 12,000 ha of pine (Pinus pinea) and juniper (Juniperus communis). Following the selection criteria for the vegetation and building type in Ambroz Valley, the next step was to search for vegetation and building combinations found throughout the Cartaya forest area.

\subsection{Analysis of Information Gathered}

\subsubsection{D Scenario Generation}

The aim of generating 3D scenarios is to provide the foundations from which a person can analyse, interpret and react to the visual experience of the landscape [8]. We chose SketchUp 8 Pro (C) (Trimble, Sunnyvale, CA, USA) as the modelling software and ArcGis 10 ( ) (ESRI, Redlands, CA, USA) as the platform for visualising and establishing the scenarios [23,24].

The landscapes were represented in various resolutions to provide an optimum resolution and ensure the computational efficiency of the digital model [8]. A digital model of terrain elevations with a $25 \mathrm{~m}$ resolution and an orthophoto with a $2.5 \mathrm{~m}$ resolution were established for the study scenarios. The actual virtual model of the sites under study comprised an orthophoto with a $1 \mathrm{~m}$ resolution. 3D objects such as buildings and trees were placed in the ArcScene module of ArcGis $10 \odot$ in the digital terrain model (DTM), which was built as a triangular irregular network (TIN). To obtain an accurate terrain representation, some embankments, tracks, and paths were edited by hand. The modelling 
and texturisation of the 3D elements was based on data gathered in the field in the two study areas, as explained in the previous section (Figure 2).

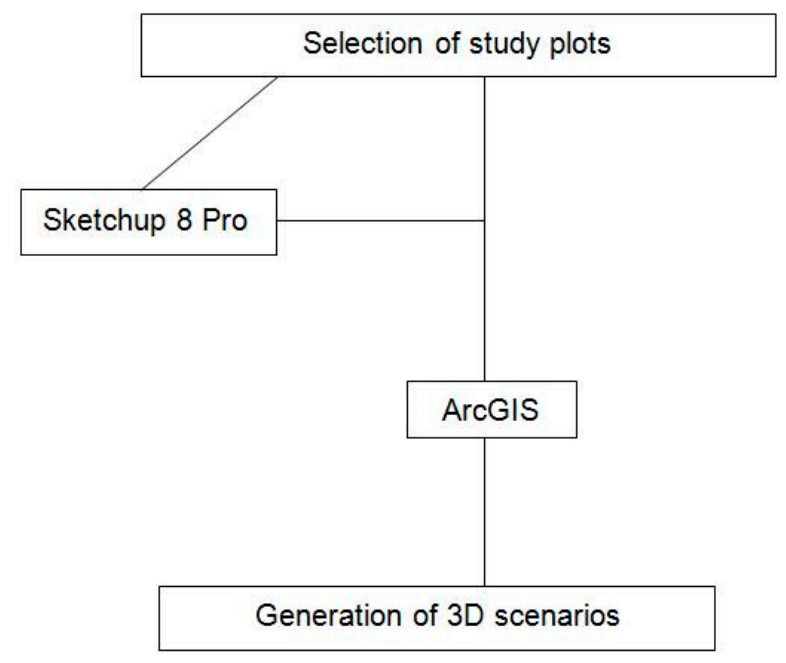

Figure 2. Generation process of 3D scenarios.

To obtain an accurate representation of the existing vegetation, the trees inside the study plots were photographed. The photos were used to compile a textures library of local woody plants such as Quercus pyrenaica, Pinus pinea, and Castanea sativa. Once the models had been produced as described, minor alterations in composition could be carried out with comparative ease (Figure 3).

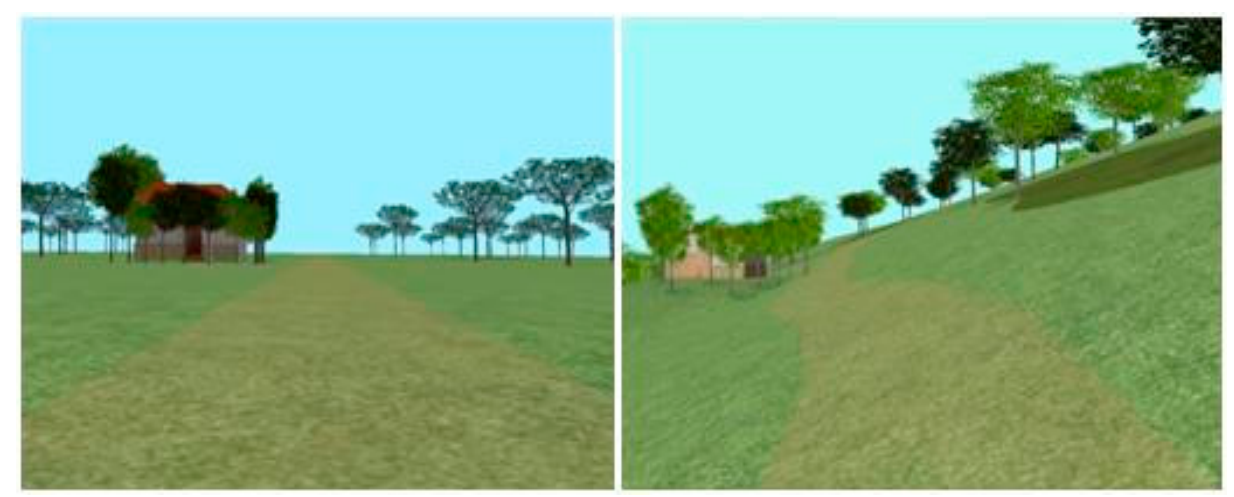

Figure 3. Left: scenario modelled in $3 \mathrm{D}$ in south Huelva and the representation of a pine wood. Right: scenario modelled in 3D of north Extremadura and the representation of mixed woodland with oak and chestnut. Source: Compiled by the author from SketchUp 8 Pro @ software 3D elements and NCGI (National Centre for Geographical Information) data.

\subsubsection{Video Variations and Generation}

Steinitz et al. [25] defined a scenario as "a scheme or diagram for a future landscape". Ringland [26] emphasised the importance of communicating the contents of the scenario: "The scenarios are the ideas, and ideas are very hard to communicate".

In the last 10 years, there has been an increase in the representations of visual scenarios. Some include digital photomontage $[13,27]$ and the generation of various scenarios and video in $3 \mathrm{D}[5,28,29]$. The use of the 3D generation of scenarios and videos for landscape visualisation and environmental planning is constantly increasing [30-33].

In this study, two virtual scenarios were modelled and characterised with native vegetation and a construction typical of the areas. The following variations were added to the scenarios: 
1. For north Extremadura, mixed woodland of oak and sweet chestnut was designed as the most representative species of the plots under study. A typical building of the area was modelled in this scenario, and vegetation screens of a varying density (low and high), species (pine, chestnut and mixed composition: oak and chestnut), and layout (linear and irregular) were placed around it. Once the scenarios were established, videos were generated at different speeds to simulate outdoor tourism activities, e.g., hiking, cycling, horse riding, or travelling by quad, motorbike, or car (Table 1).

Table 1. Each capital letter represents an outdoor activity performed at a certain speed for a specific duration.

\begin{tabular}{ccc}
\hline Capital Letter & Open Air Activity & Speed and Duration \\
\hline A & Simulating a person walking & $60 \mathrm{~s}$ \\
B & Simulating a person cycling or horse-riding & $40 \mathrm{~s}$ \\
C & Simulating a person on quad, motorbike, car & $20 \mathrm{~s}$ \\
\hline
\end{tabular}

This produced a total of nine videos for each scenario, as seen in Figure 4. Each capital letter represents a video (A, B, C) at a specific speed and tree density around the building. No capital letters are repeated in the same row or column [34]. This matrix pattern, called "Latin square" (Figure 4), makes it possible to obtain and compare statistically robust results about which the compositions, species, and types of activity (speed) are the most highly rated for the integration of each building into the surroundings. The whole procedure is performed at minimum cost in terms of the number of simulations.

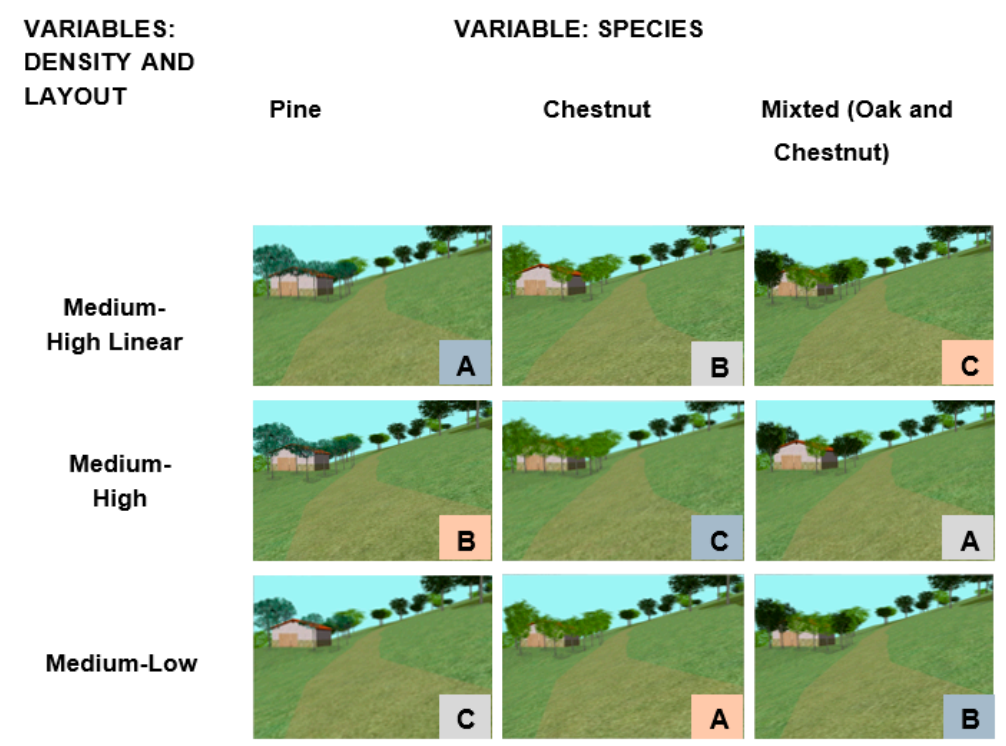

Figure 4. Thumbprints showing the layouts and densities of vegetation around the building in the scenario modelled for north Extremadura. Each capital letter represents a video with a specific speed and duration. Source: Compiled by the author from SketchUp 8 Pro $\odot$ software 3D elements and NCGI (National Centre for Geographical Information) data.

2. For the south Huelva scenario, a pine forest was designed, as pine is the most representative species in the study plots. In this scenario, a building typical of the surroundings was also modelled, and vegetation screens of a varying density, species, and layout were placed around it for comparison and to determine the most suitable layout and species for integrating the building into its surroundings. To standardise the method, the video generation process described for the north Extremadura scenario was repeated. 


\subsection{Methodology of the Survey}

A pilot study revealed that nine videos per person was too many in terms of respondent tiredness [8,35]. Therefore, the total number of surveys per study area (north Extremadura and south Huelva) was three. To complete the matrix design in each survey, three videos were presented according to the colour of the cells, as seen in Table 2. This makes it possible to compartmentalise the design, maximising the variability of the cases presented according to the variables under study and minimising respondents' visual effort.

Table 2. Latin square design for case analysis. Different colours indicate different surveys. Each respondent viewed only cases of the same colour.

\begin{tabular}{cccc}
\hline Tree Density & Pine & Chestnut & Mixed (Oak and Chestnut) \\
\hline Medium-high linear & A & B & C \\
Medium-high irregular & B & C & A \\
Medium-low & C & A & B \\
\hline
\end{tabular}

The nine videos prepared following the matrix design were submitted to a survey divided into two sections, and a web platform was designed to host it. The introductory section comprised an explanation of the survey and an additional page asking respondents for their personal data, such as their gender, age, place of residence, education, and occupation.

In the main section of the survey, respondents were asked to rate outdoor tourism activities in three of the proposed itineraries according to a sequence of randomly assigned videos (Table 2). To do this, respondents had to answer the following question after viewing each video: "How would you rate this destination for doing outdoor tourism activities?". To avoid influencing the response, videos were shown to each participant in a random order [8,36-39]. All videos were displayed horizontally on separate pages so that they could be viewed in full screen mode. A five-option rating scale was included below each video: "Very Bad, Bad, Acceptable, Good, and Very Good" [12]. Although rating scales with smaller intervals can be used (e.g., Roth, [40], who used a 10-point scale), Lange et al. (2008) pointed out that multiple levels in a rating scale can confuse respondents when they rate scenarios. On a five-option rating scale, each option corresponds to a verbal description, suggestive of an underlying quasi-metric scale [8].

The survey concluded with an open question to debug the results: "Would you change anything in the videos you have just seen? (If so, briefly explain)."

The surveys were conducted in Spanish, the language of the respondents chosen for the study.

The surveys were conducted anonymously over the Internet for users of RedIRIS (RedIRIS is the Spanish academic and research network that provides advanced communication services to the scientific community and national universities) [12,27].

\section{Respondent Characteristics}

For the south Huelva study area, survey results were obtained from 85 respondents who completed one of the three surveys specific to this location. Most of the respondents (72) were 25-55 years old (46 men, 39 women). Most (45) lived in urban areas of 10,000-500,000 inhabitants and were university educated (58).

In the north Extremadura study area, results were obtained from 84 respondents. Most (62) were 25-55 years old (42 men, 42 women). As in south Huelva, most of the respondents (41) came from urban areas of 10,000-500,000 inhabitants and were university educated (44).

As the sample was not representative of all ages and levels of education, no analysis was applied to detect any population effects on these variables. The lack of data for education levels other than those sampled prevents a more extensive analysis. Future studies could incorporate a greater diversity of respondents. 


\subsection{Statistical Methodology}

In the Latin square design, extracted from Table 2, every cell or intersection in the matrix represents variations in the three factors of analysis: the tree density (rows), species around the building (columns), and speed of itinerary (cells).

The Latin square is a random design of three independent factors at a minimal sampling cost. The design is therefore appropriate for a factorial analysis of variances (ANOVA). This was performed using SPSS 19 () statistical software. The strength of this analysis for the study was reinforced with a random presentation of three videos per respondent, creating variation in the three variables under study (density, species, and speed). This minimised the sampling errors and avoided directed response patterns $[13,41]$.

\section{Results and Discussion}

\subsection{Data Analysis: North Huelva}

The responses of 85 respondents were analysed. The five response options were Very bad, Bad, Acceptable, Good, and Very good. ANOVA was only significant for the factor of density (Table 3).

Table 3. Results of one-way ANOVA tests for the factor of Density in the Huelva sample.

\begin{tabular}{cccccc}
\hline Source & Sum of Squares & df & Mean Square & F & Sig. \\
\hline between-subjects & 156.078 & 2 & 78.039 & 110.702 & 0.00 \\
within-subjects & 177.647 & 252 & 0.705 & & \\
Total & 33.725 & 254 & & & \\
\hline
\end{tabular}

Dependent Variable: answers to question 1: "Video rating"; Factor: Density; df: degrees of fredom; F statistical test of Fisher; Sig.: $p$-value of significance.

The vegetation type and speed of movement through the itinerary (and therefore the type of associated activity) had no statistical significance in the rating of the videos (data not shown). The only positive effect was to conceal the building behind vegetation, and this seemed to be independent of the layout of the vegetation, i.e., regardless of whether the screen is linear or irregular. This can be deduced from post hoc comparisons between the density factor categories, where a high irregular density has the same acceptance as a high linear density (Figure 5). The opposite applies to a low density, which was by far the lowest rated density factor category (Figure 5).

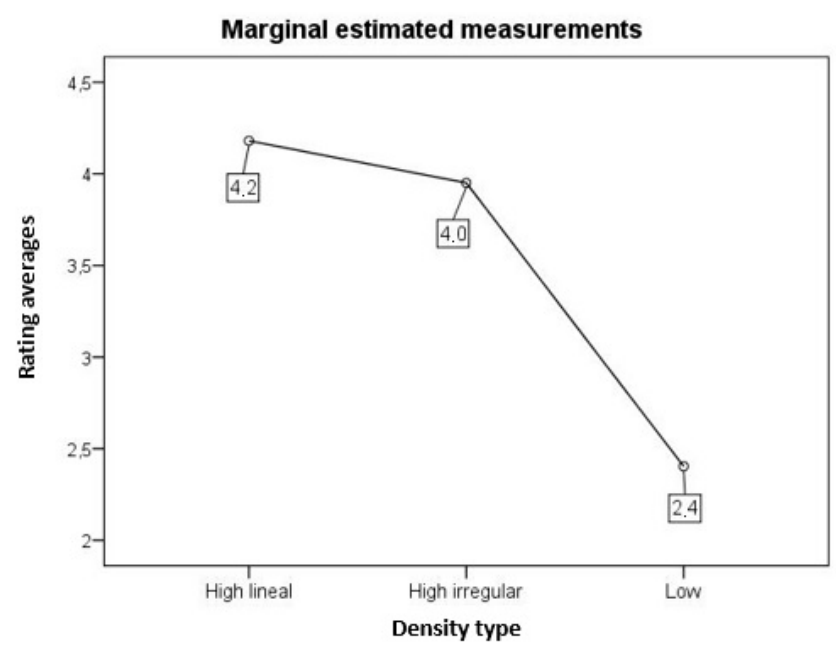

Figure 5. Comparison of rating averages (question 1) by density type (Huelva). Different letters indicate significant differences at $p<0.05$ level. 
The level of photo-realism, corresponding to the main objective of this study, was appropriate. Although many respondents answered that they would improve the quality of the videos, a significant percentage said they would not change anything, despite commenting on the simplicity of the videos (Figure 6). Thus, without the need for a high level of realism, the videos shown were sufficient to identify significant differences in the analyses of the open question asked, corresponding to the main objective of the study. Therefore, a large budget for equipment and resources does not appear to be necessary to analyze landscape preferences via quality hyper-realistic simulations [38].

\section{What would you change in the videos?}

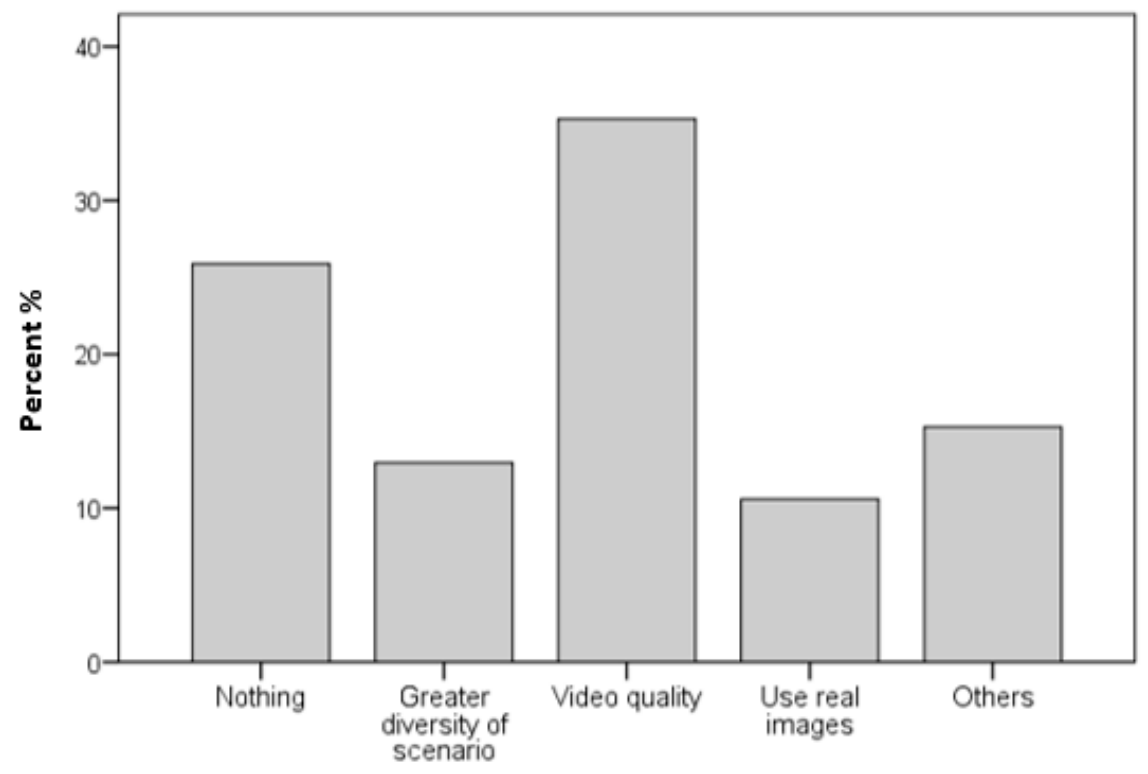

Figure 6. Count of responses to the final open-ended question. Answers are summarized in five categories by the most common responses (south Huelva). Under the heading "Others", these were: change the speed, duration of the video, and possibility of interacting and moving freely around the itinerary $\left(360^{\circ}\right.$ turns).

\subsection{Data Analysis: North Extremadura}

The responses of 84 respondents were analyzed. The five options were the same as in south Huelva. The results were similar to those obtained for Huelva, as only the density had a significant weight in the rating of scenarios or videos (Table 4).

Table 4. Results of the one-way ANOVA test for the factor of Density in the north Extremadura sample; (rest of the factors without statistical significance for the study are not shown).

\begin{tabular}{cccccc}
\hline Source & Sum of Squares & df & Mean Square & F & Sig. \\
\hline between-subjects & 201.532 & 2 & 100.766 & 133.851 & 0.000 \\
within-subjects & 187.452 & 249 & 0.753 & & \\
Total & 388.984 & 251 & & & \\
\hline
\end{tabular}

Dependent Variable: answers to question 1: "Video rating"; Factor: Density; df: degrees of fredom; F statistical test of Fisher; Sig.: $p$-value of significance.

Post hoc comparisons of analysis reveal that a high irregular density has the same acceptance as a high linear density. The opposite occurs for a low density, which was by far the lowest rated density factor category, concurring with the results for south Huelva (Figure 7). 


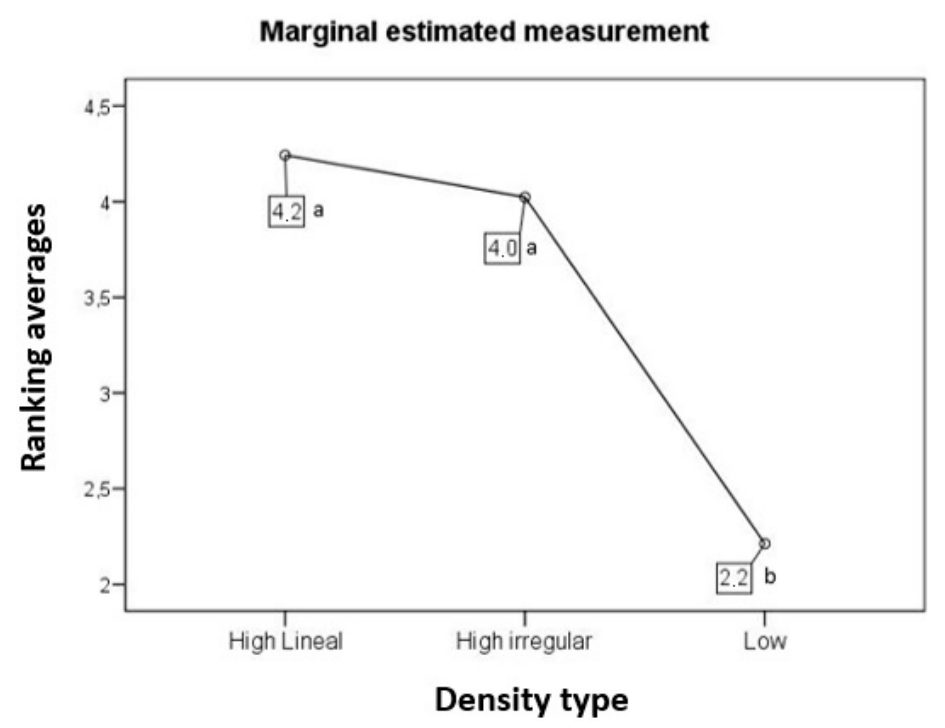

Figure 7. Comparison of rating averages by density type (north Extremadura). Different letters indicate significant differences at $p<0.05$ level.

The most common response to the final question was that respondents would change nothing or at most change the quality of the videos (Figure 8). However, in the case of north Extremadura, the frequencies are inverted: more people answered that they would make no change. Therefore, the results for Huelva could indicate that the videos were perceived as more simplistic, although in both areas, the simulation was sufficient for the objectives of the study.

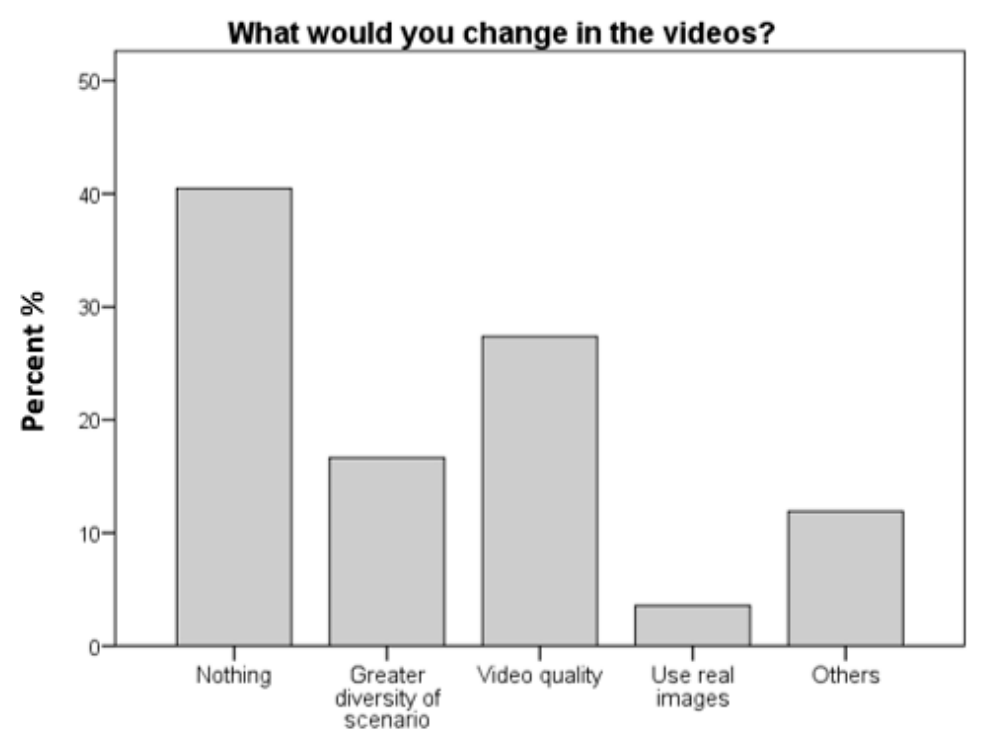

Figure 8. Count of responses to the final open-ended question. Answers are summarised in five categories by the most common responses (north Extremadura). Under the heading "Others", these were: change the speed, duration of the video, and possibility of interacting and moving around the itinerary with $360^{\circ}$ movement $\left(360^{\circ}\right.$ turns).

\subsection{Conjoint Analysis of Data}

The results obtained in an ANOVA including the two study areas have an almost identical response factor, corroborating the results obtained in Sections 3.1 and 3.2. Thus, the results of one-way ANOVA comparing the mean ratings of the videos of the north Extremadura sample versus the Huelva sample showed non-significant differences (Table 5). 
Table 5. Results of the one-way ANOVA test for the factor of Location.

\begin{tabular}{cccccc}
\hline & Sum of Squares & df & Mean Square & F & Sig. \\
\hline Inter-grupos & 0.000 & 1 & 0.000 & 0.000 & 0.986 \\
Intra-grupos & 722.710 & 505 & 1.431 & & \\
Total & 722.710 & 506 & & & \\
\hline
\end{tabular}

Dependent Variable: answers to question 1: "Video rating"; Factor: Density; df: degrees of fredom; F statistical test of Fisher; Sig.: $p$-value of significance.

The results show that, of the three variables studied, only the density is significant (Figures 5 and 7). Therefore, in the analyses performed, neither the vegetation layout nor speed (or the type of associated activity) were significant (data not shown). Only the concealment of the building influenced the respondents' rating of the scenarios, regardless of the species used.

Answers to the open question show that the level of photorealism in the study was sufficient for the proposed purpose [42]. Although many respondents said they would improve the quality of the videos, a significant percentage said they would not change anything, despite commenting on the simplicity of the videos (Figures 6 and 8). Thus, without requiring great realism, the videos shown were sufficient to identify significant differences in the analyses of the open question asked, corresponding to the main objective of the study. The results concur with those obtained by other authors $[37,43,44]$ in that a large budget for equipment and resources is not necessary for analysing landscape preferences via quality hyper-realistic simulations, which can in some cases be counterproductive and surplus to the objective of the study.

The results obtained by comparing the answers for both scenarios show similar answering tendencies (Table 5). The topography and the use of various tree species for the woodland composition, where the scenarios differ, had no significant influence on the rating of the scenarios (Figure 3).

\section{Conclusions}

The indiscriminate proliferation of new buildings is a real threat to rural heritage and touristic development in areas of great visual beauty. Furthermore, the existing legislation is very vague as to the visual integration of buildings in the landscape. The criteria proposed are not always the best and seldom carry out an effective follow-up of legislative compliance [45]. Therefore, these results represent an advance regarding the layout and density of vegetation that could be applied around the constructions to minimize the landscape impacts.

The work of authors such as Lange [10], García [12], and Barroso [13] shows static photorealistic simulations from the point of view of an average observer. The results of this study are a step forward in landscape visualisation and simulation from the point of view of an observer in motion. The proposed method, based on the creation of 3D elements in SketchUp 8 Pro $@$ within the DTM created in ArcGis 10 @ for the simulation of videos in the ArcScene module, from the point of view of an observer in motion at varying speeds, has proven to be sufficiently consistent and user-friendly to recommend its use in studies with similar aims from a landscape planning perspective.

One of the main conclusions of this study is its contribution for planners and landscape designers. The use of 3D modelling is shown to be a useful tool to facilitate the integration of buildings into the landscape. In the scenarios of north Extremadura and south Huelva, the highest-scoring vegetation screen placed around a building was one of high density, regardless of the layout.

The results show that vegetation improves the integration of buildings into the landscape. This is consistent with findings from previous studies that used photography exclusively $[12,36,46,47]$. Considering this bibliography, one could conclude that this phenomenon is practically global. In addition, for the pilot areas selected in this work representative of the Mediterranean climate, it could be specified that in these territories, the highest-scoring vegetation screen placed around a building was one of a high density, regardless of the layout. 
The concealment of buildings was rated highly, as neither the species used nor the speed of motion (and therefore the type of activity associated or topographical differences between the scenarios) were significant in the analysis of the results obtained.

\section{Future Lines}

I. Future lines of research could be the incorporation of new native plant species, characteristic of riverine areas such as alder (Alnus glutinosa) and poplars (Populus alba), in order to expand the study areas and scenarios considered. It is also possible to advance the method of conducting the surveys, looking for not only the public opinion, but also recording their behavior and attitude during the completion of them.

II. Generate an interactive virtual environment that allows respondents to modify the modeled scenarios and different elements, in addition to allowing them to freely navigate inside the modeling space.

Acknowledgments: Publication of this article has been possible thanks to the support of the European Regional Development Fund 'A way to achieve Europe' (ERDF) and the Government of Extremadura (Ref. GR15179).

Author Contributions: This work is the result of the collaboration between all authors. All authors have equally contributed, reviewed, and improved the manuscript. All authors have revised and approved the final manuscript.

Conflicts of Interest: The authors declare no conflict of interest.

\section{References}

1. Schmind, W.A. The emerging role of visual resource assessment and visualization in landscape planning in Switzerland. Landsc. Urban Plan. 2001, 54, 213-221. [CrossRef]

2. Tassinari, P.; Torreggiani, D.; Stefano, B. Dealing with agriculture, environment and landscape in spatial planning: A discussion about the Italian case study. Land Use Policy 2013, 30, 739-747. [CrossRef]

3. García, L.; Hernández, J.; Ayuga, F. Analysis of the exterior color of agroindustrial buildings: A computer aided approach to landscape integration. J. Environ. Manag. 2003, 69, 93-104. [CrossRef]

4. Hernández, J.; García, L.; Ayuga, F. Assessment of the visual impact made on the landscape by new buildings: A methodology for site selection. Landsc. Urban Plan. 2004, 68, 15-28. [CrossRef]

5. Pullar, D.V.; Tidey, M.E. Coupling 3D visualization to qualitative assessment of built environment designs. Landsc. Urban Plan. 2001, 55, 29-40. [CrossRef]

6. Bishop, I.D.; Lange, E. Visualization in Landscape and Environmental Planning: Technology and Applications; Taylor and Francis: London, UK, 2005.

7. Español, E. Las obras Públicas en el Paisaje: Guía Para el Análisis y Evaluación del Impacto Ambiental en el Paisaje; Centro de Publicaciones, Ministerio de Fomento: Madrid, Spain, 1998.

8. Lange, E.; Hehl-Lange, S.; Brewer, M.J. Scenario-visualization for the assessment of perceived green space qualities at the urban-rural fringe. J. Environ. Manag. 2008, 89, 245-256. [CrossRef] [PubMed]

9. Repton, H. Observations on the Theory and Practice of Landscape Gardening: Including Some Remarks on Grecian and Gothic Architecture; Printed by T. Bensley, Bolt Court, for J. Taylor; The Architectural Library, High Holborn: London, UK, 1805.

10. Lange, E. The limits of realism: perceptions of virtual landscapes. Landsc. Urban Plan. 2001, 54, 163-182. [CrossRef]

11. Appleton, K.; Lovett, A.; Sünnenberg, G.; Dockerty, T. Rural landscape visualization from GIS databases: A comparison of approaches, options and problems. Comput. Environ. Urban Syst. 2002, 26, 141-162. [CrossRef]

12. García, L.; Montero, M.J.; Hernández, J.; López, S. Analysis of lines and forms in buildings to rural landscape integration. Span. J. Agric. Res. 2010, 8, 833-847. [CrossRef]

13. Barroso, F.L.; Pinto-Correia, T.; Ramos, I.L.; Surová, D.; Menezes, H. Dealing with landscape fuzziness in user preference studies: Photo-based questionnaires in the Mediterranean context. Landsc. Urban Plan. 2012, 104, 329-342. [CrossRef]

14. Bishop, I.D. Understanding Place and Agreeing Purpose: The Role of Virtual Worlds. In Landscape Analysis and Visualisation; Springer: Berlin, Germany, 2008; pp. 457-467. 
15. Lange, E. 99 volumes later: We can visualize. Now What? Landsc. Urban Plan. 2011, 100, 403-406. [CrossRef]

16. Sheppard, S.R.J.; Cizek, P. The ethics of Google Earth: Crossing thresholds from spatial data to landscape visualization. J. Environ. Manag. 2009, 90, 2102-2117. [CrossRef] [PubMed]

17. Layar. The Layar App. Available online: http://www.layar.com/products/app/_ (accessed on 13 July 2014).

18. Lovett, A.; Appleton, K.; Warren-Kretzchmar, B.; Von Haaren, C. Using 3D visualization methods in landscape planning: An evaluation of options and practical issues. Landsc. Urban Plan. 2015, 142, 85-94. [CrossRef]

19. Conniff, A.; Craig, T.; Laing, R.; Galán-Díaz, C. A comparison of active navigation and passive observation of desktop models of future built environments. Des. Stud. 2010, 31, 419-438. [CrossRef]

20. Gosling, D. Techniques of analysis and communication in urban design. Landsc. Urban Plan. 1993, 26, 215-230. [CrossRef]

21. Heft, H.; Nasar, J.L. Evaluating environmental scenes using dynamic versus static displays. Environ. Behav. 2000, 32, 301-322. [CrossRef]

22. Samavatekbatan, A.; Gholami, S.; Karimimoshaver, M. Assessing the visual impact of physical features of tall buildings: Height, top, color. Environ. Impact Assess. Rev. 2016, 57, 53-62. [CrossRef]

23. Chang, H.; Gao, J.; Pan, P. Experiment and research of Google SketchUp combine with ArcGIS in the Three-Dimensional urban geographic information system. In Proceedings of the World Congress on Software Engineering, Xiamen, China, 19-21 May 2009.

24. Li, J.; Ying, B.; Yang, W.; Ning, Z.; Cui, W. The application of ArcGIS and SketchUp in the virtual campus construction (Case of Shanxi Normal University). In Proceedings of the International Conference on Multimedia Technology (ICMT), Hangzhou, China, 26-28 July 2011.

25. Steinits, C.; Anderson, R.; Arias, H.; Bassett, S.; Flaxman, M.; Goode, T.; Maddock, T.; Mouat, D.; Peiser, R.; Shearer, A. Alternative Futures for Landscapes in the Upper San Pedro River Basin of Arizona and Sonora; Island Press: Washington, DC, USA, 2005; pp. 93-100.

26. Ringland, G. Scenario Planning: Managing for the Future; John Wiley \& Sons: Chichester, UK, 1998.

27. Montero, M.J.; García-Moruno, L.; López-Casares, S.; Hernández Blanco, J. Visual impact assessment of color and scale of buildings on the rural landscape. Environ. Eng. Manag. J. 2016, 15, 1537-1550.

28. Ghadirian, P.; Bishop, I.D. Integration of augmented reality and GIS: A new approach to realistic landscape visualization. Landsc. Urban Plan. 2008, 86, 226-232. [CrossRef]

29. Zhang, S.; Huang, X. Development of virtual Campus System Based on ArcGIS. Phys. Procedia 2012, 33, 1133-1139. [CrossRef]

30. Hayek, W.U. Which is the appropriate 3D visualization type for participatory landscape planning workshops? A portfolio of their effectiveness. Environ. Plan. B Plan. Des. 2011, 38, 921-939. [CrossRef]

31. Chen, Z.; Xu, B.; Devereux, B. Urban landscape pattern analysis based on 3D landscape models. Appl. Geogr. 2014, 55, 82-91. [CrossRef]

32. Gill, L.; Lange, E. Getting virtual 3D landscapes out of the lab. Comput. Environ. Urban Syst. 2015, 54, $356-362$. [CrossRef]

33. Lindquist, M.; Lange, E.; Kang, J. From 3D landscape visualization to environmental simulation: The contribution of sound to the perception of virtual environments. Landsc. Urban Plan. 2016, 148, 216-231. [CrossRef]

34. Nasar, J.L.; Stamps-III, A.E. Infill McMansions: Style and the psychophysics of size. J. Environ. Psychol. 2009, 29, 110-123. [CrossRef]

35. Wherrett, J.R. Creating landscape preference models using internet survey techniques. Landsc. Res. 2000, 25, 79-96. [CrossRef]

36. Arriaza, M.; Cañas-Ortega, J.F.; Cañas-Madueño, J.A.; Ruiz-Avilés, P. Assessing the visual quality of rural landscapes. Landsc. Urban Plan. 2004, 69, 115-125. [CrossRef]

37. Paar, P. Landscape visualizations: Applications and requirements of 3D visualization software for environmental planning. Comput. Environ. Urban Syst. 2006, 30, 815-839. [CrossRef]

38. Christopher, J.P.; Christopher, M.R.; Brett, A.B.; Hayden, L. Identifying strengths and weaknesses of landscape visualisation for effective communication of future alternatives. Landsc. Urban Plan. 2011, 100, 231-241.

39. Pinto-Correia, T.; Barroso, F.; Surová, D.; Menezes, H. The fuzziness of Montado landscapes: Progress in assessing user preferences through photo-based surveys. Agrofor. Syst. 2011, 82, 209-224. [CrossRef] 
40. Roth, M. Validating the use of Internet survey techniques in visual landscape assessment-An empirical study from Germany. Landsc. Urban Plan. 2006, 78, 179-192. [CrossRef]

41. Stamps, A.E.; Nasar, J.L. Design review and public preferences: effects of geographical location, public consensus, sensation seeking, and architectural styles. J. Environ. Psychol. 1997, 17, 11-32. [CrossRef]

42. Appleton, K.; Lovett, A. GIS-based visualization of rural landscapes: Defining "sufficient" realism for environmental decision-making. Landsc. Urban Plan. 2003, 65, 117-131. [CrossRef]

43. Perkins, N.H. Three questions on the use of photo-realistic simulations as real world surrogates. Landsc. Urban Plan. 1992, 21, 265-267. [CrossRef]

44. Cubuku, E. Does the level of visual detail in virtual environments affect the user's spatial knowledge? Environ. Plan. B Plan. Des. 2011, 38,741-752. [CrossRef]

45. Reyes-Rodriguez, A.M. Criterios de Diseño de las Construcciones Rurales Atendiendo a Los Costes de sus Acabados y a su Integración en el Paisaje. Ph.D. Thesis, University of Extremadura, Badajoz, Spain, 2009.

46. Smardon, R.C. Perception and Aesthetics of the Urban Environment: Review of the Role of Vegetation. Landsc. Urban Plan. 1988, 15, 85-106. [CrossRef]

47. Hernández, J.; García, L.; Morán, J.; Juan, A.; Ayuga, F. Estimating visual perception of rural landscapes: The influence of vegetation. The case of Elsa Valley (Spain). J. Food Agric. Environ. 2003, 1, 139-141.

(C) 2017 by the authors. Licensee MDPI, Basel, Switzerland. This article is an open access article distributed under the terms and conditions of the Creative Commons Attribution (CC BY) license (http:/ / creativecommons.org/licenses/by/4.0/). 